\title{
Konsep Etnomatematika Batik Tradisional Jawa Sebagai Pengembangan Media Pembelajaran Matematika
}

\author{
Ari Irawan', Mei Lestari' ${ }^{2}$, Wanti Rahayu ${ }^{3}$ \\ ari_irawan@unindra.ac.id ${ }^{1}$ \\ Program Studi Teknik Informatika Universitas Indraprasta PGRI ${ }^{1,2,3}$
}

The Concept Of Traditional Java Batik Ethnomathematics As Learning Media

\begin{abstract}
The purpose of this study is to reveal the types of batik patterns that can be used as a medium for learning mathematics, especially in the transformation geometry material. In addition, making applications for learning mathematics using ethnomathematical elements in traditional batik patterns in West Java, Central Java and East Java. This research method is RnD (Research and Development) with ADDIE approach (Analysis, Design, Development, Implementation, Evaluation). The stages that will be discussed in this research are identification, classification, and analysis of batik patterns in Java. The results of this study are the identification of batik patterns on the island of Java, classifying types and existing batik motifs and analyzing batik motifs using elements of an ethnomathematical approach. The result suggests batik patterns can be used as a medium for learning mathematics by using an ethnomathematical element approach as learning both mathematics education and student character education.
\end{abstract}

Keywords: Ethnomatics Concept, Learning Media, Traditional Batik, Javanese Batik

Received date: 22 Juli 2021

Article Info

Revised date: 3 Januari $2022 \quad$ Accepted date: 27 Januari 2022

\section{PENDAHULUAN}

Kondisi saat ini pandemic covid-19 membuat sekolah melakukan pembelajaran dilakukan dari rumah. Hal ini bukan tanpa masalah baik bagi orang tua, siswa, guru dan pihak sekolah. Guru perlu menyajikan pembelajaran yang aktif, efektif dan efisien sebagaimana tatap muka disekolah dilakukan. Kenyataanya guru belum memilki media pembelajaran yang efektif dan efisien ketika memberikan materi khusunya pada mata pelajaran matematika. Agar pembelajaran matematika berhasil pada masa pandemi maka diharapkan guru membuat pembelajaran daring matematika lebih menarik, efektif dan menyenangkan (Fauzy \& Nurfauziah, 2021). implementasi pembelajaran daring mulai dari perencanaan, pengorganisasian, penggerak, dan pengawasan (Hastowo \& Abduh, 2021).

Penelitian yang telah membuktikan bahwa metode pembelajaran dengantatap muka atau konvensional ini masih tetap menjadi pilihan utama sebagian besar siswa (Napitupulu, 2021). Hal ini memberikan pengakuan bahwasanya pembelajaran dengan tatap muka lebih diminati sebagain besar siswa jika dibandingkan pembelajaran daring saat ini yang dilakukan

Pembelajaran daring bukan tampa masalah dimana ini harus ada kesiapan dari sekolah, orang tua dari segi ekonomi dan kesipan guru untuk mengajar apakah sudah memiliki cara efektikdan dan efisien dalam melakukan kegiatan pembelajarn (Zahra Alhumairah dkk, 2021). Guru dapat menggunakan media pembelajaran khususnya video pembelajaran (Purbayanti et al., 2020). Ada guru juga yang memberikan penjelasan, mateir dan tugas memlaui whatsapp grup terkadang juga tatap muka memalau zoom meeting, google meet dan google class room sebagai sarana pembelajaran secara daring (Wiryanto, 2020). Atas dasar untuk menjawab tantangan pemerintah akan menerapkan pembelajaran hybrid maka penulis melakukan riset membuat media pembelajaran berbasis android dengan pendekatan budaya/ kearifan lokal yaitu batik tradisional yang ada di Pulau Jawa.

Media pembelajaran dalam penelitian ini yaitu menggunakan produk pengembangan buku, berupa buku sambung titik dengan materi budaya lokal motif batik Jombang. Buku sambung titik dapat digunakan sebagai media pengenalan batik dan ragam hias (Pratiwi \& Ratyaningrum, 2021). Motif batik Pasedahan Suropati yang memiliki konsep geometri untuk sekolah dasar, tentunya dapat digunakan 
dalam pembelejaran geometri seperti pada pengenalan garis, pengenalan sudut, dan pengenalan bangun datar sederhana (Ulum et al., 2017). Batik trusmi cirebon mengandung unsur-unsur matematis, dianataranya adalah konsep-konsep geometri simetri, transformasi (refleksi, translasi, dan rotasi), serta kekongruenan (Arwanto, n.d.). Aplikasi Ngabatik merupakan aplikasi pengenalan motif batik digital yangmemerlukan koneksi internet untuk bisa dioperasikan oleh pengguna (Febriansari \& Atmojo, 2021). Berdasarkan riset yang telah dilakukan sebelumnya terlihat sudah begitu banyak yang meneliti tentang etnomatematika batik. Riset ini berfocus pada pembuatan aplikasi berbasis android dimana batik digunakan sebgaai dasar pengembangan pembelajaran matematika berbasis etnomatematika. Riset ini belum selesai sehingga pada artikel ini baru menyajikan tahapan pengumpulan data dan analisis serta desain yang akan buat.

\section{KAJIAN PUSTAKA}

Etnomatematika adalah matematika yang muncul dari aktivitas manusia di lingkungan yang dipengaruhi oleh budaya(Fauzi \& Lu'luilmaknun, 2019). Etnomatematika muncul sebagai konsep baru yang merupakan pengaruh timbal balik antara matematika, pendidikan, budaya, dan politik. Etnomatematika dinyatakan sebagai sebuah kajian terhadap ide-ide matematik pada masyarakat primitive. Ide-ide matematik terdapat pada setiap budaya, akan tetapi yang diutamakan adalah bagaimana mereka mengungkapkannya dan konteks-konteks khusus yang terdapat pada suatu budaya akan berbeda dengan budaya yang lain. Perbedaannya bukan terletak pada kemampuan untuk berpikir abstrak secara logis, tetapi terletak pada pemikiran subjek, anggapan dasar budaya, dan situasi apa yang muncul saat proses berpikir (Prabawati, 2016). etnomatematika adalah berbagai hasil aktivitas matematika yang dimiliki atau berkembang di masyarakat Sidoarjo, meliputi konsep- konsep matematika pada peninggalan budaya berupa candi dan prasasti, gerabah dan peralatan tradisional, satuan lokal, motif kain batik dan bordir, serta permainan tradisional (Rachmawati, 2012). Mathematics is an abstraction of the human mind, is used as a tool for problem solving. The value delivered in learning mathematics include: practical and use vales, the value of discipline, cultural values, social values, moral values, values aesthetic (art/beauty), and the value of recreation (entertainment) (Abdullah, 2017). Ethnomathematics juga dapat dianggap sebagai sebuah program yang bertujuan untuk mempelajari bagaimana siswa untuk memahami memahami, mengartikulasikan, mengolah, dan akhirnya menggunakan ide-ide matematika, konsep, dan praktek-praktek yang dapat memecahkan masalah yang berkaitan dengan aktivitas sehari-hari mereka (Ekowati et al., 2017).Berdasarkan pendapat-pendapat tersebut terkait etnomatematika maka dapat disimpulkan bahwa etnometemtika merupakan matematika yang ada dalam unsur budaya masyarakat baik itu budaya yang bersifat adat istiadat kebiasaan dan juga benda lainya yang terdapat unsur matematika dalam budaya tersebut.

Batik adalah kain yang berlukiskan motif yang dibuat dengan cara menahan warna dengan lilin malam. Batik merupakan sebuah kesenian yang sarat akan makna. Batik bukan sekedar corak yang digambar oleh seniman batik. Melainkan tersirat sebuah pesan yang tersembunyi dalm motif atau gambar (Nurul anisa, 2020). Batik merupakan salah satu wujud dari peninggalan budaya bangsa Indonesia yang harus dilestarikan, karena merupakan hasil dari seni budaya tradisional masa lalu bangsa Indonesia. Indonesia mempunyai beraneka ragam kebudayaan yang memiliki ciri dan karakter masingmasing dan salah satunya adalah batik (Amalia, 2010). Batik sangat dikagumi bukan hanya karenan prosesnya yang rumit tetapi juga dalam motif dan warnanya yang unik dan indah, yang sarat akan makna simbolik. Setiap motif batik mengandung nilai simbolis magis yang ditujukan untuk fungsi kepercayaan dan nilai-nilai estetis yang digunakan sebagai hiasan (Miranti et al., 2021). Batik stamp is one batik type that is produced by using specific stamp tool (Anugraha et al., 2015). Berdasarkan pendapat-pendapat tersebut mengenai batik maka dapat disimpulkan bahwa batik merupakan salah satu budaya bangsa dengan berbagai macam corak/ motif serta teknik pembuatan, alat dan bahan serta filosofi dari sebuah karya seni. Batik merupakan identitas bangsa yang menanamkan nilai-nilai budaya dan karakter sebagai pendidikan.

\section{METODE PENELITIAN}

Penelitian ini menggunakan metode $\mathrm{RnD}$ (Research and Development) dengan pendekatan ADDIE (Analisys, Design, Development, Implementation and Evaluation) (Dahlan \& Permatasari, 
2018). Penelitian saat ini masih sedang berlangsung dan saat ini sedang pada tahapan analisis dan desain dari aplikasi yang akan dibuat. Proses pengumpulkan data berdasarkan dokumentasi, studi literatur, wawancara dan observasi lapangan. Penelitian ini dilakukan pada masa PPKM darurat sehingga banyak pengambilan data dilakukan secraa daring dan koordinasi dilakukan secara daring dengan pihak-pihak terkait. Analisis data dilakukan dengan Teknik triangulasi terkait dengan hasil observasi dan wawancara terhadap subjek peneltian serta para pakar yang berkompeten dibidangnya. Pakar/ validator dibagi menjadi tiga orang yaitu pakar materi, pakar desain media pembelajaran dan pakar etnomatematika. Instrumen yang digunakan dlam riset ini adalah menggunakan pedoman wawancara yang disusun untuk menemukan kaitan matematika dengan budaya khusunya batik tradisonal masing-masing daerah. Lokasi yang menjadi riset ini adalah cagar budaya berupa batik yang ada di provinsi Jawa Barat, Jawa Tengah dan Jawa Timur. Masing-maisng lokasi ini diambil sampel beberapa kota/ kabupaten secara pusposif dimana daerah yang banyak memiki motif batik yang terdapat unsur etnomatematika. Teknik analisis data dilakukan dengan triangulasi artinya peneliti melakukan pengolahan data berupa citra batik yang digunakan sebagai sarana untuk membuat media pembelajaran matematika.

\section{HASIL PENELITIAN DAN PEMBAHASAN}

\section{Hasil Penelitian}

Hasil dari penelitian ini nantinya adalah aplikasi pembelajaran matematika dengan konsep etnomatematika pada batik khas Jawa. Tahapan riset yang dilakukan oleh tim peneliti sampai saat ini pengumpulan data, analisis data sertda merancang desin yang akan digunakan untuk pengembangan media pembelajaran dengan aplikasi berbasis android. Dihadirkannya media dakon dalam proses pembelajaran RME dapat mendukung berlangsungnya pembelajaran matematika materi perkalian yang optimal (Trisnani \& Sari, 2021). Keterkaitan matematika dengan kehidupan sehari-hari dikatan sebagai Realistic Mathematics Education hal ini terkait dengan media pembelajaran yang akan dibuat dengan pendekatan unsur etnomatematika batik tradisional yang sudah ada dalam kebudayaan masyarakat. Media pembelajaran ini diharapkan dapat memberikan pendidikan karakter dan juga pendidikan matematika khusunya.

Proses pengumpulan data yang dilakukan oleh tim yaitu menginventarisir motif batik yang ada di Jawa Barat, Jawa Tengah dan Jawa Timur. Selanjutknya melakukan identifikasi terhadap masingmasing motif batik tersebut untk mengklasifikikan berdasarkan asal daerah, nama motif batik, sejarah batik dan unsur matematika apa yang terkandung dalam motif batik tersebut. Tahapan pengumpulan data ini menggunakan teknik studi literiatur, dokumentasi, observsi dan wawancara terkiat motif-motif batik yang ada di Pulau Jawa.

Tahapan analisis disin dibagi menjadi tiga bagian. Yaitu tahapan mengumpulkan data batik yang ada di di pulau Jawa, tahapan kedua yaitu melakukan gray $n$ scale terhadao motif batik yang ada dan tahapan selanjutnya adalah analisis motif batik dam melihat pola serta garis lekukan yang ada pada motif batik tersebut sehingga dapat di komparasikan antara motif batik satu dengan yang lainnya apakah terdapat kemiripan secara detail motif ataupun unsur etnomatematika atau tidak sehingga motif tersebut dapat dikatakan berasal dari rumpun motif batik yang sama.

Salah satu kearifan budaya lokal yang penuh akan nilai pendidikan karakter adalah seni batik (Miranti et al., 2021). Batik merupakan menjadi bagian penting identitas bangsa Indonesia. Beragam corak motif dan sejarah dari sebuah motif batik memperkaya khazanah kebudayaan bangsa. Demikian batik dapat dijadikan sarana pembelajaran baik untuk pendidikan karakter seperti yang telah di ungkapkan sebelumnya juga sebagai sarana kegiatan pembelajaran khusunya pembelajaran matematika.

Ada beberapa motif batik yang dapat dijadikan pembelajaran matematika khusunya pada materi geometri datar dimana terdapat unsur matematiika berupa refleksi, dilatasi dan transformasi. Kegiatan pembelajaran dengan menggunakan motif batik sebagai sarana media pembelajaran telah cukup banyak berhasil dilakukan seperti yang telah dilakukan penelitian sebelumnya. Pengembangan e-modul matematika yang mengintegrasi motif Batik Adi Purwo yang bertujuan untuk mengembangkan sebuah media pembelajaran yang layak untuk digunakan dalam pembelajaran matematika pada materi transformasi geometri untuk siswa SMP (Sintiya et al., 2021). Penelitian tersebut membuat e-modul matematika yang menggunakan salah satu motif batik dimana penelitian tersebut berhasil digunakan sebagai media pembelajaran yang tepat untuk meningkakan kemampuan siswa pada materi transformasi geometri. 
Konsep Etnomatematika Batik Tradisional Jawa Sebagai Pengembangan Media Pembelajaran Matematika (Ari Irawan, Mei Lestari, Wanti Rahayu)

Ini menjadi tantangan tersendiri bagi peneliti untuk membuat aplikasi pembelajaran matematika dimana yang menjadi media adalah motif batik yang khusunya berada di Pulau Jawa. Hal ini diakukan sebagai upaya untuk memberikan sesuatu yang baru bagi dunia pendidikan khususnya matematika bahwa terdapat integrasi seni budaya batik dengan matematika yang memang tidak dapat dilepaskan dalam kehidupans sehari-hari. Siswa mulai memahami dan mengerti suatu konsep matematika dalam kehidupan sehari-harinya berupa kegiatan budaya yang terdapat pembelajaran matematika. Kenyataan yang terjadi di sekolah, sebagian besar guru masih belum bias mengkaitkan mata pelajaran matematika dengan budaya lokal yang ada (Suwito \& Trapsilasiwi, 2016). Fakta dilapangan memang masih banyak guru yang belum memberikan pembelajaran dengan mengintegrasikan budaya dalam kehidupan seharihari sebagai media pembelajaran. Ini berkaitan dengan keterampilan guru dan proses pembelajaran guru untuk dapat memberikan pelajaran dimana dapat mengaitkan kehidupan siswa dengan matematika sehingga siswa tidak hanya belajar konsep akan tetapi siswa mempelajari kontkes matematika dalam kehidupan sehari-hari yang lebih dikenal dengan istilah matematika realistik.

Pembahasan

Berbagai motif batik digunakan sebagai media pembelajaran matematika. Batik Pekalongan memiliki motif ragam hias yang tak jauh beda dengan batik lainnya yang menggunakan motif stilisasi tumbuhan dan binatang (Amalia, 2010).Batik Ngawi memiliki beraneka ragam motif, ada yang bercorak alam, sejarah, potensi daerah dan lainnya. Setiap corak memiliki beberapa motif, misalnya saja batik Ngawi corak alam terdiri dari motif teh pucuk jamus, mawar dan kupu-kupu, bambu, daun jati, melon, dan masih banyak lagi (Hartatik et al., 2021). Adapula yang membuat apliakasi batik untuk pengenalam motif batik. Aplikasi Ngabatik merupakan aplikasi pengenalan motif batik digital yang memerlukan koneksi internet untuk bisa dioperasikan oleh pengguna (Febriansari \& Atmojo, 2021). Berbagai penelitian terkait degan batik dan pengembangan batik sebagai media pembelajaran telah dilakukan. Riset yang dilakukan pada penelitian kali ini berfokus pada data base motif batik yang ada di Jawa Barat, Jawa Tegah dan Jawa Timur. Masing-masing daerah memilki motif dan corak batik yang berbeda-beda namun memang tidak di pungkiri ada beberapa motif yang mirip. Riset ini berfocus pada motif batik yang digunakan sebagai media pembelajaran matematika khusunya pada materi geometri datar pada siswa sekolah dasar dan menengah.

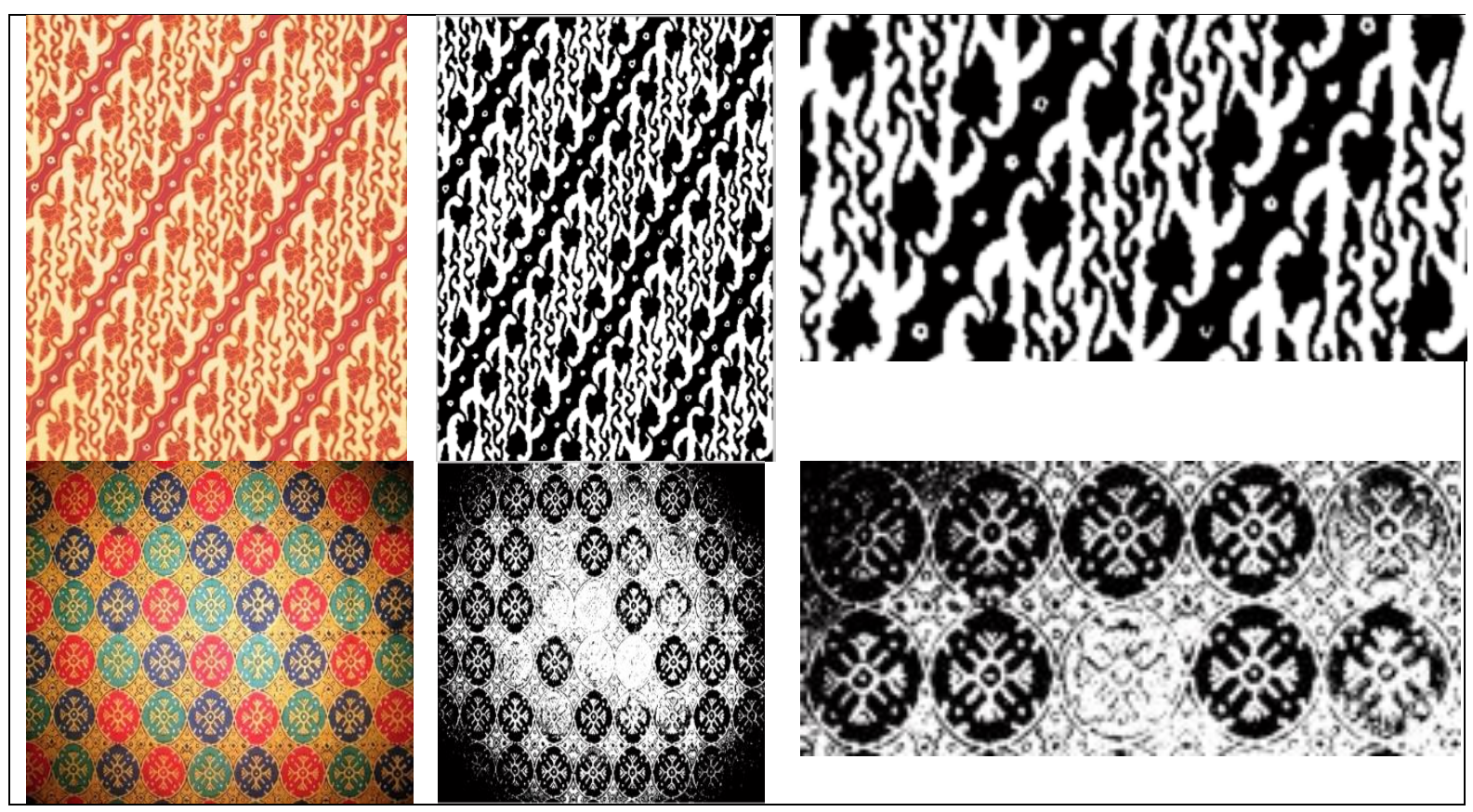

Gambar 1. Motif Batik Priyangan dari Tasikmalaya dan Motif Jlamprang dari Pekalongan Sumber: http://tasikmalaya20.blogspot.com/p/blog-page_3.html dan https://inibaru.id/pasar-kreatif/menengok-cantiknya-batik-khas-pekalongan

Gambar 1 terlihat jelas motif batik Priyangan yang berasal dari Jawa Barat dan Motif Jlamprangan dari Jawa Tengah dimana terlihar pola yang simateris. Hal ini menyatakan bahwa dari zaman dahulu kala masyarakat telah mengenal pola simetris sebagai bagian dari desain/ motif batik. 
Pola ini tersusun rapih sehingga menjadi sangat indah. Jika dilihat lebih dekat maka akan terlihat desain dari motif batik ini merupakan tumbuhan atau bentuk-bentuk tertentu yang memilki makna. Berdasarkan motif tersebut maka dapat digunakan geometri transformasi dalam motif yang digunakan. Sehingga terlihat rapih dan elegan motif batik tersebut. Pola-pola inilah yang menjadi bagian dari etnomatematika batik. Terlihat pula pada motif batik Jlamprang terlihat bahwa terdapat unsur lingkaran yang didalamnya terdapat motif garis. Demikian batik dapat digunakan sebagai media pembelajaran matematika unuk materi geometri transformasi. Pada setiap daerah di Indonesia, batik memiliki corak motif yang berbeda-beda sehingga batik memiliki keanekaragaman motif. Selainkeanekaragaman motif batik juga memiliki warna bervariatif yang menggambarkan kekhasan tiap daerah tersebut (Pratiwi \& Ratyaningrum, 2021). Secara logis siswa dapat membatikdengan terampil dan mendapatkan hasil belajar membatik yang tinggi (Endriyani, 2015). Berdasarkan pendapat tersebut terlihat bahwa batik merupakan salah satu kekayaan warisan budaya bangsa yang dapat digunakan sebagai salah satu media pembelajaran matematika khusunya pada materi geometri datar.

Kegiatan pembelajaran matematika diharapkan mampu mengintgrasikan budaya, matematik ditambalgi dengan perkembangan teknologi infomasi dan komunikasi untuk dapat memberikan solusi media pembelajaran khusunya saat ini dimasa pandemic covid-19. Tidak dapat dipungkiri saat ini sudah terjadi pergerseran dalam perkembangan pendidikan. Pembelajaran dapat dilakukan dimana saja dan kapan saja dengan adanya telepon genggam. Bak pisau bemata dua maka perkemangan teknologi infomasi dan komunikasi hendaknya dimanfaatkan semaksimal mungkin untuk berbagai kegiatan posiftif dalam pembelajaran daring yang saat ini masih dilakukan. Penelitian telah banyak dilakukan bagaimana implementasi pembelajaran matematika dilakukan pada masa pandemic dan tatap muka terbatas yang telah di tetapkan oleh pemerintah.

Pendekatan etnomatematika digunakan sebagai suatu cara untuk siswa dapat belajar langsung dari budaya sekitar dan bisa menumbuhkan rasa ketertarikan sehingga menumbuhkan semngat belajar. Pada media pembelajaran ini pendekatan etnomatematika matematika yang diangkat yaitu konsep transformasi geometri yang terdapat pada Kain Besurek Bengkulu serta Kain Batik Ciamis melalui triangulasi dari berbagai sumber yaitu dokumen,masyarakat, dan kalangan akademis (Ratnaningsih et al., 2021). Berdasarkan penelitian tersebut maka dapat dikatakan bahwa media pembelajaran berbasis android dikatakan efektif sebagai media pembelajaran khususnya pada materi geomteri transformasi dengan menggunakan batik sebagai konsep matematika menggunakan unsur etnomatematika. Langkah selantnya yang akan tim peneliti lakukan adalah membuat konsep tampilan layar dan story board aplikasi motif batik sebagai media pembelajaran matematika.

\section{SIMPULAN DAN SARAN}

Berdasarkan hasil dan pembahasan yang telah tim peneliti lakukan dapat disimpulkan bahwa batik dapat digunakan sebagai media pembelajaran matematika khusunya pada materi geometri transformasi. Batik juga digunakan sebagai penanaman pendidikan karakter bagi siswa untuk dapat mencintai dan melestarikan budaya dan kearifan local daerah khususnya di Jawa Barat, Jawa Tengah dan Jawa Timur. Penelitian ini masih sedang berlangsung untuk tahapan desain dan pengembangan dari aplikasi yang akan dibuat dengan menggunakan android sebagai dasar pengembangan aplikai media pembelajaran ini. Kami harapkan penelitian selanjutnya dapat mengembangkan berbagai potensi budaya yang memiliki keterkaitan denga nmatematika, Sehingga lebih banyak lagi riset yang mampu melesatrikan budaya dan mengintegrasikan budaya kedalam pembelajaran matematika.

\section{UCAPAN TERIMAKASIH}

Apresiasi dan terima kasih kepada Direktorat Jenderal Pendidikan Tinggi, Riset dan Teknologi, Kementerian Pendidikan, Kebudayaan, Riset dan Teknologi, yang telah membiayai kegiatan Penelitian. Terapan Unggulan Perguruan Tinggi Tahun 2021 dengan judul: "Etnomatematika pada motif batik khas jawa sebagai pengembangan media pembelajaran interaktif berbasis android". Terima kasih juga kepada LLDIKTI Wilayah III Jakarta dan Lembaga Penelitian dan Pengabdian Masyarakat Universitas Indraprasta PGRI yang telah membantu kegiatan penelitian ini melalui Kontrak Penelitian: Nomor: 248/LL3/PG/2021, Tanggal 23 Maret 2021. Dan Surat Perjanjian/Kontrak Penelitian UNINDRA Nomor: 005/SKP.LT/LPPM/UNINDRA/III/2021, Tanggal 29 Maret 2021. 
Konsep Etnomatematika Batik Tradisional Jawa Sebagai Pengembangan Media Pembelajaran Matematika (Ari Irawan, Mei Lestari, Wanti Rahayu)

\section{DAFTAR PUSTAKA}

Abdullah, A. S. (2017). Ethnomathematics in perspective of sundanese culture. Journal on Mathematics Education, 8(1), 1-16. https://doi.org/10.22342/jme.8.1.3877.1-15

Amalia, R. U. (2010). Motif batik Pekalongan : studi dokumen koleksi museum batik Pekalongan. Seni Dan Budaya, VI(2), 125-141.

Anugraha, R. A., Sutan, W., \& Mufidah, I. (2015). The Design of Batik Stamp tool Scraping Working Table Using Ergonomics Principles. Procedia Manufacturing, 4(Iess), 543-551. https://doi.org/10.1016/j.promfg.2015.11.074

Arwanto. (n.d.). Eksplorasi etnomatematika batik trusmi cirebon untuk mengungkap nilai filosofi dan konsep matematis. 40-49.

Dahlan, J. A., \& Permatasari, R. (2018). Pengembangan bahan ajar berbasis etnomatematika dalam pembelajaran matematika sekolah menengah pertama. JNPM (Jurnal Nasional Pendidikan Matematika), 2(1), 133-150.

Ekowati, D. W., Kusumaningtyas, D. I., \& Sulistyani, N. (2017). Ethnomathematica dalam pembelajaran matematika (pembelajaran bilangan dengan media batik Madura, tari khas trenggal dan tari khas Madura). Jurnal Pemikiran Dan Pengembangan SD, 5(2), 716-721.

Endriyani, E. (2015). Upaya meningkatkan keterampilan mencolet dan hasil belajar membatik melalui model pembelajaran contextual teaching and learning berbatuan video. Scholaria: Jurnal Ilmu Pendidikan Dan Kebudayaan, 5(2), 36-45.

Fauzi, A., \& Lu'luilmaknun, U. (2019). Etnomatematika Pada Permainan Dengklaq Sebagai Media Pembelajaran Matematika. AKSIOMA: Jurnal Program Studi Pendidikan Matematika, 8(3), 408. https://doi.org/10.24127/ajpm.v8i3.2303

Fauzy, A., \& Nurfauziah, P. (2021). Kesulitan Pembelajaran Daring Matematika Pada Masa Pandemi COVID-19 di SMP Muslimin Cililin. Jurnal Cendekia : Jurnal Pendidikan Matematika, 5(1), 551-561. https://doi.org/10.31004/cendekia.v5i1.514

Febriansari, D., \& Atmojo, I. ragil W. (2021). Ngabatik: Aplikasi pengenalan motif batik Ngawi berbasis android. Syntax Literate: Jurnal Ilmiah Indonesia, 6(2), 620-636.

Hartatik, T., Winarni, R., \& Surya, A. (2021). Studi nilai karater pada simbolisme batik Ngawi motif srambang park dalam pembelajaran seni rupa. Jurnal Kependidikan: Jurnal Hasil Peneltian Dan Kajian Pustaka Di Bidang Pendidikan, Pengajaran Dan Pembelajaran, 7(1), 227-238.

Hastowo, A. T., \& Abduh, M. (2021). Analisis Kemampuan Manajerial Kepala Sekolah Dalam Implementasi Pembelajaran Daring The Analysis Of Principal's Managerial Ability In Online Learning Implementation. Scholaria: Jurnal Pendidikan Dan Kebudayaan, 11(3), 252-263.

Miranti, A., Lilik, L., Winarni, R., \& Surya, A. (2021). Representasi pendidikan karakter berbasis kearifan lolal dalam motif batik Wahyu Ngawiyatan sebagai muatan pendidikan senirupa di Sekolah Dasar. Jurnal Basicedu, 5(3), 546-560.

Napitupulu, R. M. (2021). Dampak pandemi Covid-19 terhadap kepuasan pembelajaran jarak jauh. Scholaria: Jurnal Pendidikan Dan Kebudayaan, 11(2), 115-122. https://doi.org/10.21831/jitp.v7i1.32771

Nurul anisa, N. anisa. (2020). Eksplorasi Motif Batik Pakidulan Geopark Ciletuh Palabuhanratu. Jurnal PEKA (Pendidikan Matematika), 4(1), 21-26. https://doi.org/10.37150/jp.v4i1.809

Prabawati, M. N. (2016). Etnomatematika masyarakat pengrajin anyaman rajapolah kabupaten tasikmalaya. Infinity, 5(1), 25-31.

Pratiwi, D. K., \& Ratyaningrum, F. (2021). Buku Sambung Titik: Media Pengenalan Motif Batik Jombangan Untuk Anak Usia 3-6 Tahun. Jurnal Seni Rupa, 9(2), 205-219. https://jurnalmahasiswa.unesa.ac.id/index.php/va/article/view/36357 
Purbayanti, H. S., Ponoharjo, P., \& Oktaviani, D. N. (2020). Analisis Kebutuhan Video Pembelajaran Matematika Pada Pandemi Covid-19. JIPMat, 5(2), 165-172. https://doi.org/10.26877/jipmat.v5i2.6693

Rachmawati, I. (2012). Eksplorasi Etnomatematika Masyarakat Sidoarjo. MATHEdunesa, 1(1), 1-8.

Ratnaningsih, N., Nuradriani, M., \& Nurazizah, I. S. (2021). Pengembagan Media Pembelajaran pada Materi Transformasi dengan Berbantuan I-Spring Menggunakan Pendekatan Etnomatematika Berbasis Android. Jurnal Jendela Pendidikan, 01(02), 32-42.

Sintiya, M. W., Astuti, E. P., \& Purwoko, R. Y. (2021). Pengembangan E -modul Berbasis Etnomatematika Motif Batik Adi Purwo untuk Siswa SMP. Jurnal Pendidikan Raflesia, 06(01), $1-15$.

Suwito, A., \& Trapsilasiwi, D. (2016). Pengembangan model pembelajaran matematika SMP kelas VII berbasis kehidupan masyarakat JAWARA (Jawa dan Madura) di Kabupaten Jember. JIPM (Jurnal Ilmiah Pendidikan Matematika), 4(2), 79-84.

Trisnani, N., \& Sari, E. F. (2021). Keefektifan Model Realistic Mathematics Education Berbantuan Media Dakon Terhadap Hasil Belajar Perkalian. Scholaria: Jurnal Pendidikan Dan Kebudayaan, 11(2), 173-178.

Ulum, B., Budiarto, M. T., \& Ekawati, R. (2017). Etnomatematika Pasuruan : Eksplorasi Geometri Untuk Sekolah Dasar Pada Motif Batik Pasedahan Suropati. Seminar Nasional Integrasi Matematika Dan Nilai Islam, 1(1), 70-78.

Wiryanto. (2020). Proses Pembelajaran Matematika Di Sekolah Dasar Di Tengah Pandemi Covid-19. Jurnal Review Pendidikan Dasar: Jurnal Kajian Pendidikan Dan Hasil Penelitian, 6(2), 125 132.

Zahra Alhumairah dkk. (2021). Perkembangan Pembelajaran Daring Terhadap Minat Belajar Matematika Siswa SMP Pada Masa Pandemi Covid-19. Jurnal Ilmu Pendidikan, 3(3), 943950 . 